\title{
Dynamics of a Snowball Earth Ocean
}

\section{Citation}

Ashkenazy, Yosef, Hezi Gildor, Martin Losch, Francis Alexander Macdonald, Daniel P. Schrag, and Eli Tziperman. 2013. "Dynamics of a Snowball Earth Ocean." Nature 495 (7439): 90-93.

\section{Published Version}

doi:10.1038/nature11894

\section{Permanent link}

http://nrs.harvard.edu/urn-3:HUL.InstRepos:13454620

\section{Terms of Use}

This article was downloaded from Harvard University's DASH repository, and is made available under the terms and conditions applicable to Open Access Policy Articles, as set forth at http:// nrs.harvard.edu/urn-3:HUL.InstRepos:dash.current.terms-of-use\#OAP

\section{Share Your Story}

The Harvard community has made this article openly available.

Please share how this access benefits you. Submit a story.

Accessibility 


\section{Dynamics of a Snowball Ocean}

Yosef Ashkenazy, ${ }^{1 *}$ Hezi Gildor, ${ }^{2}$ Martin Losch, ${ }^{3}$ Francis A. Macdonald, ${ }^{4}$ Daniel P. Schrag, ${ }^{4,5}$ \& Eli Tziperman $^{4,5 *}$

${ }^{1}$ Department of Solar Energy and Environmental Physics, The Blaustein Institutes for Desert Research, Ben-Gurion University of the Negev, Midreshet Ben-Gurion, 84990, Israel.

${ }^{2}$ Institute of Earth Sciences, The Hebrew University of Jerusalem, Jerusalem, 91904, Israel.

${ }^{3}$ Alfred-Wegener-Institut für Polar-und Meeresforschung, Bremerhaven, Germany.

${ }^{4}$ Earth and Planetary Sciences, Harvard University, 20 Oxford St, Cambridge, MA, 02138, USA.

${ }^{5}$ School of Engineering and Applied Sciences, Harvard University, 20 Oxford St, Cambridge, MA, 02138, USA.

* To whom correspondence should be addressed. 
Geological evidence suggests that marine ice extended to the equator at least twice during the Neoproterozoic $(\sim 750-635 \text { Myr ago })^{1,2}$, inspiring the Snowball Earth hypothesis that the Earth was globally ice covered ${ }^{3,4}$. In a possible Snowball Earth climate, ocean circulation and mixing processes would have determined the melting and freezing rates that determine ice thickness ${ }^{5,6}$, influenced the survival of photosynthetic life ${ }^{4,5,7-9}$, and may provide important constraints for the interpretation of geochemical and sedimentological observations ${ }^{4,10}$. Here we show that in a Snowball Earth, the ocean would have been well mixed and characterized by a dynamic circulation $^{11}$, with vigorous equatorial meridional overturning circulation, zonal equatorial jets, a well-developed eddy field, strong coastal upwelling and convective mixing. This is in contrast to the sluggish ocean often expected in a snowball scenario ${ }^{3}$. As a result of vigorous convective mixing, the ocean temperature, salinity and density were either uniform in the vertical or weakly stratified in a few locations. Our results are based on a coupled ice flow-ocean circulation model driven by a weak geothermal heat flux under a global $\sim 1 \mathrm{~km}$ ice cover. Compared to the modern ocean, the snowball ocean had far larger vertical mixing rates, and comparable horizontal mixing by ocean eddies. The strong circulation and coastal upwelling resulted in melting rates near continents as much as ten times larger than previously estimated ${ }^{6,7}$. While we cannot resolve the ongoing debate on the existence of a global snowball ice cover ${ }^{10,12,13}$, we discuss the implications to nutrient supply for photosynthetic activity and to banded iron formations. The new insights and constraints on ocean dynamics may help resolve the Snowball Earth controversy when combined with future geochemical and geological observations. 
The flow of thick ice over a Snowball ocean ("sea glaciers", characterized by very different dynamics from thinner sea ice ${ }^{14}$ ), has received significant attention over the past few years ${ }^{5-}$ 7,9,14,15. Similarly, the role and dynamics of atmospheric circulation and heat transport, $\mathrm{CO}_{2}$ concentration, cloud feedbacks, and continental configuration have been studied ${ }^{16-18}$, as has the role of dust over the Snowball ice cover ${ }^{17}$, 19 . In contrast, despite its importance, the ocean circulation during Snowball events has received little attention. The few studies that used full ocean General Circulation Models (GCMs) concentrated mostly on the ocean role in Snowball initiation and aftermath ${ }^{20,21}$. None of these studied accounted for the combined effects of thick ice cover flow and driving by geothermal heating ${ }^{11,13,22,23}$, yet ${ }^{11}$ simulated an ocean under a $200 \mathrm{~m}$ thick ice cover with no geothermal heat flux, and calculated a non steady-state solution with near-uniform temperature and salinity, and vanishing Eulerian circulation together with a strong parameterized eddy-induced high latitude circulation cells.

To allow simulating the special circumstances during Snowball events, we use a novel coupled ocean-thick ice flow model (Methods Summary section, and on-line Methods Section, together referred to hereafter as MS). We begin by exploring the snowball circulation using an easier to understand 2D (latitude-depth) ocean model with no continents. The results point to the importance of ocean eddy motions, and given that these have never been studied for a snowball ocean, we investigate them using a high resolution sector ocean model. Finally, we consider a near-global 3D ocean model with reconstructed Neoproterozoic continental geometry to verify that our insights remain valid in this more realistic configuration. 
Consider first the zonally averaged temperature, salinity and circulation, including the meridional overturning circulation (MOC). Fig. 1 shows steady state results from a 2D (latitude-depth) version of the ocean model coupled to a 1D (latitude) ice flow model, driven by geothermal heating $\left(\sim 0.1 \mathrm{~W} / \mathrm{m}^{2}\right)$ that is enhanced over a prescribed bottom ridge (Fig. SI-2 in on-line Supplementary Information). We assume land ice at a volume equivalent to about 1 $\mathrm{km}$ of sea level (MS), and our model predicts that the upper $\sim 1 \mathrm{~km}$ of the ocean is frozen as well. Concentrating salt in a significantly lower ocean volume results in ocean salinity that is significantly higher than that of the present-day (Fig. 1b). The high salinity and high pressure at the bottom of the ice lower the freezing temperature to $\sim-3.5^{\circ} \mathrm{C}$, explaining the cold temperature field (Fig. 1a). Variations in temperature and salinity are fairly weak ${ }^{11}$, as expected given the insulating thick ice cover and weak geothermal heat forcing.

The enhanced geothermal heat flux over the ridge acts to create low-density water at the ocean bottom, and therefore leads to convective vertical mixing that makes the temperature and salinity effectively vertically uniform nearly everywhere, creating a water-mass pattern that is completely different from that expected during any other period in Earth history (Figs. 1a,b). Near the enhanced geothermal heating over the ridge (bounded by the thick contour in Figs. 1a,b), there is a weakly stable stratification due to melt water production over the enhanced heating.

The MOC (Fig. 1d) is surprisingly strong and is confined to around the equator, very different from the high-latitude present-day MOC. The meridional velocity, which together with the vertical velocity composes the MOC, therefore decays very rapidly away from the equator. The most prominent feature in the zonal velocity field is the two strong jet-like flows near the equator, flowing at opposite directions on the two sides of the equator, and decaying slowly 
away from the equator (Fig. 1c). The zonal velocity in the higher latitudes, away from the equatorial jet-like structures, is generally eastward throughout most of the water column apart from near the bottom. This eastward mid-to high-latitude velocity is in geostrophic equilibrium between the Coriolis force and the pressure gradient, and is driven by the largescale meridional density and therefore pressure gradient that is a consequence of heating and melting over the ridge which lower the density there (MS).

To understand the equatorial zonal flows and MOC, note that their dominant momentum balance is geostrophic in the north-south direction, and hydrostatic in the vertical, as is the case in the present-day ocean. The east-west momentum balance, however, is between the Coriolis force and eddy (turbulent) viscosity, which is negligible in most of the present-day ocean. The dominant momentum balances are therefore,

$$
-f v=v_{h} u_{y y}, \quad f u=-p_{y} / \rho_{0}, \quad p_{z}=-g \rho,
$$

where the (east, north, vertical) coordinates and velocities are denoted $(x, y, z)$ and $(u, v, w), g$ is gravitational acceleration, $v_{\mathrm{h}}=2 \times 10^{4} \mathrm{~m}^{2} \mathrm{~s}^{-1}$ the horizontal eddy viscosity coefficient, $f \approx \beta y$ is the Coriolis parameter using the equatorial $\beta$ plane approximation, $\rho$ is the density, $\rho_{0}$ a reference density, and $p$ is the pressure. The meridional scale obtained from the zonal momentum equation is $L \sim\left(v_{h} / \beta\right)^{1 / 3} \sim 100 \mathrm{~km}$, consistent with the extent of the MOC in the numerical solution. Assuming the meridional pressure gradient set by the differential geothermal heating to be approximately constant in latitude near the equator, we can solve the above equations (MS) to find

$$
u \sim g \rho_{y}(z+H / 2) /\left(\beta \rho_{0}\right) \frac{1}{y}, \quad v \sim 2 v_{h} g \rho_{y}(z+H / 2) /\left(\beta^{2} \rho_{0}\right) \frac{1}{y^{4}},
$$


where $H$ is the ocean depth. The more rapid decay of the meridional velocity $v$ as function of latitude $y$ in these expressions explains why the MOC is restricted to the equatorial region, while the equatorial zonal flows $(u)$ extend farther poleward. These solutions also predict that $u$ changes sign across the equator (where $y=0$ ) but $v$ does not, and also that both horizontal velocities change sign with depth, at $z=-H / 2$, all remarkably consistent with Figs. $1 \mathrm{c}, \mathrm{d}$.

The ice thickness in these solutions (Fig. 1e) is quite uniform, varying from 1120 to $1200 \mathrm{~m}$, due to the homogenizing effect of the ice flow ${ }^{6}$, consistent with previous studies ${ }^{7}, 15$. High latitude basal freezing and low latitude melting rates are balanced by an equatorward ice flow and are comparable to, if not larger than, the ice surface sublimation and precipitation rates (Fig. 1f). These rates are quite different from previous estimates that ignored ocean dynamics ${ }^{7}$, highlighting the important role of ocean dynamics.

The above 2D model predicts the ocean turbulent eddy field to play a dominant role in the momentum budget, via its parameterization by the horizontal eddy viscosity $v_{h}$. Snowball eddy motions have never been studied before, and to examine them, we consider the results of a high resolution model shown in Fig. 2. This model demonstrates that the solution for the ocean circulation is surprisingly turbulent and time-dependent, far from the stagnant snowball ocean one might envision given the lack of wind forcing and air-sea fluxes. The zonal velocity field (Figs. 2c,f) shows several strong jets off the equator, in addition to the two equatorial jets seen in the 2D solution. These jets, reminiscent of those seen in the atmosphere of Jupiter, arise from the action of the eddies. That is, the equatorial flows are unstable and generate eddies; the meridional convergence of eddy momentum fluxes, $\partial \overline{u^{\prime} v^{\prime}} / \partial y$ generates additional jets off the equator (Fig. 2f), which again are unstable and feedback on the eddies which sustain the jets ${ }^{24}$. 
The high resolution run also shows a warm area to the northwest of the land mass, which leads to local melting rates of up to $10 \mathrm{~cm} /$ year (Fig. 2e), about ten times larger than the maximum melting rates calculated by coarse model runs ${ }^{6,7}$. This warmer area is due to a concentrated coastal upwelling of deep water heated by geothermal heating. The upwelling occurs in response to the equatorial zonal flow away from the continent. The deep heating is allowed by a very weak local salinity-induced stratification due to geothermally driven ice melting (similar to that seen over the ridge in Fig. 1b). While intriguing, we cannot use this large melting rate to conclusively deduce the existence of thin ice or open water locally near continents as suggested by some observations ${ }^{10}$, and explain the survival of photosynthetic life during global Snowball Earth $8,9,15,25$. The explicitly resolved eddy field can be used to estimate a mixing time scale from low to high latitudes of $\sim 500$ years (MS), not very different from present-day basin-scale mixing rates.

Finally, a 3D ocean solution with a realistic continental configuration supports the results of the 2D model (Figs. 3a,b and SI-3). The zonally averaged fields (Fig. SI-3), equatorial zonal jets, large-scale westward flows in the higher latitudes, existence of an equatorial MOC, and the vertically uniform temperature, salinity and density in most areas away from the enhanced geothermal heating, are all consistent with the 2D solution discussed above. Differences from the $2 \mathrm{D}$ case include a weaker salinity range due to the concentrated geothermal heating region being confined and therefore weaker in the 3D case (spatial average is $0.1 \mathrm{~W} \mathrm{~m}^{-2}$ in both); the equatorial MOC is composed of two cells due to the more complex continental and geothermal heating configuration. Like the high resolution model discussed above, the global 3D solution in the presence of continents shows upwelling and downwelling wherever the equatorial zonal jets encounter continents. This upwelling is possible due the weak stratification of the 
snowball ocean, while in an ocean with present-day like stratification these jets would be diverted sideways via horizontal boundary currents.

The weakly stratified, convectively mixed ocean, as well as the strong coastal upwelling, strong equatorial MOC, and well developed eddy field found here, all imply that the deep and surface ocean are strongly linked in a snowball scenario, unlike in the well-stratified presentday ocean. The well-mixed snowball ocean ${ }^{11}$ has several interesting geochemical implications. First, if there are areas of photosynthesis under a local patch of thin ice, mixing or upwelling are needed to resupply limiting nutrients, as a weakly mixed ocean would lead to the exhaustion of the local nutrient pool and productivity would end. Second, the return of banded iron formations (BIFs) after a billion year absence is an iconic feature of Neoproterozoic glaciation often attributed to stagnant snowball deep water ${ }^{3}$. Assuming that melt water was derived from land ice that contained air bubbles of an oxygenated atmosphere, one might expect that with enhanced melting and a strongly mixed ocean, iron concentrations could not rise sufficiently to deposit BIFs. However, Neoproterozoic BIFs, unlike Archean and Paleoproterozoic ones, are not broadly distributed ${ }^{26}$. Instead, they form irregular lenticular bodies within glacial deposits, and are found predominantly in juvenile rift basins in close association with volcanic rocks, analogous to the Red Sea, where iron is supplied by hydrothermal fluids ${ }^{27}$. Such rift basins are somewhat isolated from the rest of the well-mixed ocean, allowing the buildup of iron levels and formation of BIFs, not inconsistent with our results showing a well-mixed ocean.

Our findings suggest that beneath the Snowball ice-cover, the Neoproterozoic oceans were dynamic, well mixed ${ }^{11}$, spatially and temporally variable, and far from a stagnant pool. These ocean dynamics insights open the way to a reinterpretation of some geochemical, sedimentary 
and paleontological observations, possibly contributing to the debate on the existence of a global ice cover and to our understanding of this very special time in Earth's history.

\section{Methods summary}

Our model couples the state-of-the-art ocean general circulation model, $\mathrm{MITgcm}^{28}$, which can simulate thick ice shelves ${ }^{29}$, with a recently developed two-dimensional (2D, latitudelongitude) ice flow model ${ }^{15}$, extending previous 1D flow models ${ }^{6,7}$. The model is run here in three configurations: 2D (latitude-depth) ocean model coupled to a 1D (latitude) ice flow model, high resolution $\left(1 / 8^{\circ}\right)$ sector model with prescribed uniform ice cover, and a 3D global model with reconstructed Neoproterozoic continental configuration coupled to a 2D ice flow model. A geothermal heat flux is prescribed in all three versions at the bottom of the ocean (Fig. SI-2), with a spatial average of $0.1 \mathrm{~W} \mathrm{~m}^{-2}$, and is spatially uniform except not far from the equator (motivated by the Neoproterozoic continental reconstruction of ${ }^{30}$ ), where the geothermal flux is up to four times its background value. The 2D ocean model also prescribes a ridge over which the heating is enhanced, while the topography of the two other models is flat. Sensitivity experiments to the location and amplitude of the enhanced heating, and to the topography in both the 2D and 3D models, show our solution to be very robust. See on-line methods section for further details. 
1. Harland, W. B. Evidence of late Precambrian glaciation and its significance. In Nairn, A. E. M. (ed.) Problems in Palaeoclimatology, 119-149, 180-184 (John Wiley \& Sons, London, 1964).

2. Evans, D. A. D. \& Raub, T. D. Neoproterozoic glacial palaeolatitudes: a global update. In Arnaud, E., Halverson, G. P. \& Shields-Zhou, G. (eds.) The Geological Record of Neoproterozoic Glaciations, vol. 36, 93-112 (London, Geological Society of London, 2011).

3. Kirschvink, J. Late Proterozoic low-latitude global glaciation: The Snowball Earth. In Schopf, J. \& Klein, C. (eds.) The Proterozoic Biosphere: A Multidisciplinary Study, 51-52 (Cambridge University Press, Cambridge, 1992).

4. Hoffman, P. \& Schrag, D. The snowball Earth hypothesis: testing the limits of global change. Terra Nova 14, 129-155 (2002).

5. McKay, C. Thickness of tropical ice and photosynthesis on a snowball Earth. Geophys. Res. Lett. 27, 2153-2156 (2000).

6. Goodman, J. \& Pierrehumbert, R. Glacial flow of floating marine ice in "Snowball Earth". J. Geophys. Res. 108, 10.1029/2002JC001471 (2003).

7. Pollard, D. \& Kasting, J. Snowball Earth: A thin-ice solution with flowing sea glaciers. J. Geophys. Res. 110, 10.1029/2004JC002525 (2005).

8. Corsetti, F., Olcott, A. \& Bakermans, C. The biotic response to Neoproterozoic snowball Earth. Palaeogeography, Palaeoclimatology, Palaeoecology 232, 114-130 (2006). 
9. Campbell, A. J., Waddington, E. D. \& Warren, S. G. Refugium for surface life on Snowball Earth in a nearly-enclosed sea? A first simple model for sea-glacier invasion. Geophys. Res. Lett. 38, 10.1029/2011GL048846 (2011).

10. Allen, P. A. \& Etienne, J. L. Sedimentary challenge to Snowball Earth. Nature Geosci. 1, $817-825$ (2008).

11. Ferreira, D., Marshall, J. \& Rose, B. Climate determinism revisited: Multiple equilibria in a complex climate model. J. Climate 24, 992-1012 (2011).

12. Pierrehumbert, R. T., Abbot, D. S., Voigt, A. \& Koll, D. Climate of the Neoproterozoic. Ann. Rev. Earth Planet. Sci. 39, 417-460 (2011).

13. Yang, J., Peltier, W. R. \& Hu, Y. The initiation of modern "Soft Snowball" and "Hard Snowball" climates in CCSM3. Part II: Climate dynamic feedbacks. J. Climate 25, 27372754 (2012).

14. Warren, S., Brandt, R., Grenfell, T. \& McKay, C. Snowball Earth: Ice thickness on the tropical ocean. J. Geophys. Res. 107, 10.1029/2001JC001123 (2002).

15. Tziperman, E. et al. Continental constriction and sea ice thickness in a Snowball-Earth scenario. J. Geophys. Res. 117, 10.1029/2011JC007730 (2012).

16. Pierrehumbert, R. Climate dynamics of a hard snowball Earth. J. Geophys. Res. 110, 10.1029/2004JD005162 (2005).

17. Le-Hir, G., Donnadieu, Y., Krinner, G. \& Ramstein, G. Toward the snowball earth deglaciation... Clim. Dyn. 35, 285-297 (2010). 
18. Donnadieu, Y., Godd'eris, Y., Ramstein, G., N’ed'elec, A. \& Meert, J. A snowball Earth climate triggered by continental break-up through changes in runoff. Nature 428, 303306 (2004).

19. Abbot, D. S. \& Pierrehumbert, R. T. Mudball: Surface dust and Snowball Earth deglaciation. J. Geophys. Res. 115, 10.1029/2009JD012007 (2010).

20. Poulsen, C., Pierrehumbert, R. T. \& Jacobs, R. L. Impact of ocean dynamics on the simulation of the Neoproterozoic "snowball Earth". Geophys. Res. Lett. 28, 1575-1578 (2001).

21. Poulsen, C. \& Jacob, R. Factors that inhibit snowball Earth simulation. Paleoceanography 19, 10.1029/2004PA001056 (2004).

22. Voigt, A., Abbot, D. S., Pierrehumbert, R. T. \& Marotzke, J. Initiation of a Marinoan Snowball Earth in a state-of-the-art atmosphere-ocean general circulation model. Clim. Past 7, 249-263 (2011). Doi:10.5194/cp-7-249-2011.

23. Le-Hir, G., Ramstein, G., Donnadieu, Y. \& Pierrehumbert, R. T. Investigating plausible mechanisms to trigger a deglaciation from a hard snowball Earth. Comptes rendus Geosci. 339, 274-287 (2007).

24. Farrell, B. F. \& Ioannou, P. J. Structural stability of turbulent jets. J. Atmos. Sci. 60, 21012118 (2003).

25. Runnegar, B. Palaeoclimate: Loophole for snowball Earth. Nature 405, 403-404 (2000). 
26. Bekker, A. et al. Iron formation: The sedimentary product of a complex interplay among mantle, tectonic, oceanic, and biospheric processes. Economic Geology 105, 467-508 (2010).

27. Young, G. M. Proterozoic plate tectonics, glaciation and iron-formations. Sedimentary Geology 58, 127-144 (1988).

28. Marshall, J., Adcroft, A., Hill, C., Perelman, L. \& Heisey, C. A finite-volume, incompressible Navier Stokes model for studies of the ocean on parallel computers. J. Geophys. Res. 102, 5,753-5,766 (1997).

29. Losch, M. Modeling ice shelf cavities in a z coordinate ocean general circulation model. J. Geophys. Res. 113, 10.1029/2007JC004368 (2008).

30. Li, Z. X. et al. Assembly, configuration, and break-up history of Rodinia: A synthesis. Precambrian Res. 160, 179-210 (2008). 
Supplementary Information is linked to the online version of the paper at www.nature.com/nature.

Acknowledgments. We thank Brian Rose and two anonymous reviewers for most constructive and helpful comments. This work was supported by NSF climate dynamics, P2C2 program, grant ATM-0902844 (ET, YA). ET thanks the Weizmann Institute for its hospitality during parts of this work. YA thanks the Harvard EPS department for a most pleasant and productive sabbatical visit.

Author contribution. Y.A. and E.T. formulated the problem and performed the model runs and analysis, F.A.M and D.P.S contributed to the geological motivation and interpretation, M.L. and H.G. helped with the model setup, and all authors contributed to the writing of the manuscript.

Author information. The authors declare no competing financial interests. Correspondence and requests for materials should be addressed to E.T. (eli@eps.harvard.edu) or Y.A. (ashkena@bgu.ac.il). 


\section{Figure 1: Results of a 2D (latitude-depth) ocean model coupled to a 1D (in latitude) ice}

flow model. (a) Potential temperature $\left({ }^{\circ} \mathrm{C}\right.$; white area on top corresponds to the calculated ice cover thickness). (b) Salinity (ppt), which varies due to freezing and melting (panel f) induced by spatially variable geothermal heating and heat flux through the ice due to the latitudedependent atmospheric temperature (MS); salinity is somewhat lower in the Northern Hemisphere because of the ridge with enhanced geothermal heating and therefore enhanced melting there. (c) Zonal velocity (cm/s). (d) MOC stream function ( $\mathrm{Sv}$, one $\mathrm{Sv}$ is $10^{6} \mathrm{~m}^{3} \mathrm{~s}^{-1}$ ), showing a strong equatorial MOC (35 Sv), compared to the present day high latitude North Atlantic MOC (about $20 \mathrm{~Sv}$ ). (e) Ice thickness (m) and ice velocity (m/yr) as functions of latitude. (f) Freezing rate (negative values imply melting) at the ice base together with prescribed sublimation/ precipitation rates at the ice surface, showing that ocean contribution to setting the ice thickness is comparable to or larger than that of the atmosphere (mm/yr).

Figure 2: Results of a 3D high resolution sector ocean model showing a rich timedependent turbulent eddy field. (a) Snapshot of the temperature field at $1200 \mathrm{~m}$ (that is, about 110 meters below the ice). (b) Same, for salinity. (c) Same, for zonal velocity (zero value marked by a white contour). (d) Time-averaged MOC. (e) Time-averaged melting rate (zero values marked by thick contour). (f) Zonal, depth and time mean of zonal velocity (cm/s, black), and of scaled convergence of eddy momentum fluxes $-\partial \overline{u^{\prime} v^{\prime}} / \partial y$ (red), both as function of latitude. The close correspondence between the two demonstrates that eddy momentum flux convergence plays a dominant role in the generation of the zonal jets. 
Figure 3: Results of the 3D ocean model coupled to a 2D (latitude-longitude) ice flow model, in the presence of reconstructed Neoproterozoic continental configuration. (a) Temperature at 1200m depth (colors), areas of enhanced geothermal heating (black contour lines) and land masses (white areas). (b) Salinity at 1200m (colors). (c) Ice thickness (colors), and ice velocity vectors (plotted every fourth/ second grid point in the longitude/ latitude direction). Results are generally consistent with the 2D solution (see also Fig. SI-3), although some deviations from zonal symmetry occur due to advection of temperature and salinity by ocean currents near continents, and due to enhanced heating and freshening via ice melting in the area of enhanced geothermal heating between the continents. 


\section{Methods}

\section{Model description}

The model used here couples the Massachusetts Institute of Technology general circulation ocean model (MITgcm) ${ }^{28}$ with its ice-shelf package ${ }^{29}$ to a recently-developed two dimensional (latitude-longitude) model of thick ice flow over a Snowball ocean ${ }^{15}$ which is an extension of the 1D ice flow model of 6,7 and similar ones ${ }^{31-33}$. The ice flow model compensates for melting and sublimation at low latitudes and freezing/ precipitation at high latitudes, with an equatorward ice flow calculated from ice thickness gradients based on Glenn's law. The ice flow model employs the well known ice-shelf approximation in which the velocity is depthindependent $^{34,35}$, together with an assumed linear vertical temperature profile within the ice ${ }^{6}$, which together make it possible to average over the vertical dimension rather than model it explicitly.

The coupling of the ice and ocean models is done asynchronously: the ocean model is run for 300 years and the ice model is then run for a similar period, and the process is repeated until a steady state is obtained. At each iteration the ocean model is given the ice thickness calculated by the ice model, while the ice model is driven by the melting and freezing rates calculate by the ocean model. The ice-surface meridional temperature $T_{s}(y)$, sublimation and snowfall are prescribed from ${ }^{7}$, with an equator-to-pole temperature difference of $36^{\circ} \mathrm{C}$ (Fig. SI-1). No-slip ocean boundary conditions are specified on side and bottom boundaries, while free-slip conditions are specified under the ice cover.

Turbulent convection is parameterized in our model experiments by an increased vertical diffusion where the vertical stratification is unstable. Eddy mixing and mixed layer 
parameterizations developed for the present-day ocean ${ }^{36}$ are likely not applicable for the very weakly stratified Snowball ocean, and we use instead crude horizontal and vertical eddy diffusion. A different choice was made by ${ }^{11}$ who used an eddy parameterization tuned to present-day ocean eddies ${ }^{36}$ and simulated a snowball ocean under a $200 \mathrm{~m}$ thick ice with no geothermal heating and therefore not at a thermodynamic equilibrium, but with a quasiequilibrated circulation. They find a very weakly stratified ocean with a vanishing Eulerian velocity field, yet with strong high-latitude parameterized eddy-driven meridional circulation cells, very different from the vigorous Eulerian equatorial overturning and jets found here.

The 2D ocean model uses a horizontal diffusion coefficient of $\kappa_{\mathrm{h}}=200 \mathrm{~m}^{2} / \mathrm{s}$ and viscosity of $v_{\mathrm{h}}=2 \times 10^{4} \mathrm{~m}^{2} / \mathrm{s}$; the 3D "realistic geometry" case uses different values of $\kappa_{\mathrm{h}}=500 \mathrm{~m}^{2} / \mathrm{s}$ and $v_{\mathrm{h}}=5 \times 10^{4} \mathrm{~m}^{2} / \mathrm{s}$ required by its different resolution. The vertical viscosity in both models is set to $v_{\mathrm{v}}=2 \cdot 10^{-3} \mathrm{~m}^{2} / \mathrm{s}$ and the vertical diffusivity to $\kappa_{\mathrm{v}}=1 \cdot 10^{-4} \mathrm{~m}^{2} / \mathrm{s}$. The high resolution case uses a Leith eddy viscosity formulation ${ }^{37}$.

The 2D ocean model (latitude-depth, periodic in longitude), has a horizontal latitudinal resolution of $1^{\circ}$ and 32 vertical levels, varying from $10 \mathrm{~m}$ adjacent to the ice to $200 \mathrm{~m}$ at depth $(\Delta \mathrm{z}=920,15 \times 10,12,17,23,32,45,61,82,110,148,7 \times 200 \mathrm{~m}$; note that the thick upper level is entirely within the ice). The 2D ocean model is coupled to a 1D (latitude) version of the ice flow model. We performed sensitivity runs to the location and amplitude of the geothermal forcing and found the solution to be very robust.

The 3D near-global ocean model was run at a horizontal resolution of $2^{\circ}$ from $82^{\circ} \mathrm{S}$ to $82^{\circ} \mathrm{N}$, and with 73 vertical levels of varying thickness from $10 \mathrm{~m}$ near the ice to $200 \mathrm{~m}$ at depth (starting from the ocean surface, $\Delta \mathrm{z}=550,57 \times 10,14,20,27,38,54,75,105,147,7 \times 200 \mathrm{~m}$; at steady 
state, the upper 33 levels are within the ice, and therefore inactivated, and the rest represent the ocean). Continental configuration is based on the 720 Ma Neoproterozoic reconstruction of ${ }^{30}$, and includes an estimated location of spreading ridges between the continents, where geothermal heating is likely enhanced (thick contour in Fig. 3a; spreading ridges elsewhere are not included due to the uncertainty in their location). Bathymetry reconstructions for the Neoproterozoic are not easy to come by, and we therefore specified a flat topography in the 3D case, relying on land masses to restrict zonal flows. We performed sensitivity runs with specified sills ( $1 \mathrm{~km}$ high) around the ocean constricted by the land masses, as well as with (1 km high) mid-ocean ridges specified in the open ocean and found that these do not change the overall picture.

The high resolution sector ocean model spans $45^{\circ}$ longitude, from $10.5^{\circ} \mathrm{S}$ to $10.5^{\circ} \mathrm{N}$, at a horizontal resolution of an eighth of a degree longitude and latitude and 20 vertical levels of $100 \mathrm{~m}$ each. An ice cover with uniform thickness of $1025 \mathrm{~m}$ is prescribed in this case rather than using the ice flow model (which would be prohibitive due to computational cost). A flat ocean topography is used, and enhanced geothermal heating is prescribed as a Gaussian centered around $6^{\circ} \mathrm{N}$, at up to 4 times the amplitude of the background geothermal flux. The surface temperature in this experiment is uniform (due to its relatively small meridional extent) and set to $-44.4^{\circ} \mathrm{C}$. This high resolution run was integrated for over 100 years to reach an equilibrium of the eddy field, yet because its ice cover is specified rather than evolving, the run is - unlike for the other two models - not at a complete thermodynamic equilibrium with its ice cover.

While geothermal heat can have some effect on the present-day ocean ${ }^{38}$, it is the dominant forcing in a snowball ocean. A hydrothermal heat flux is therefore prescribed here at the 
bottom of the ocean and is spatially uniform except where enhanced flux is prescribed to simulate the effect of spreading ridges. These enhanced geothermal areas are prescribed in the model runs shown in the paper to be not far from the equator (motivated by the Neoproterozoic continental reconstruction of ${ }^{30}$ ), and the geothermal flux there is up to four times its background value. The observed background flux away from ocean ridges is about $0.05 \mathrm{~W} \mathrm{~m}^{-2}$, and the flux observed at mid-ocean ridges is about 4 times larger, such that the average over ocean basins is estimated to be of the order of $0.1 \mathrm{Wm}^{-2}$ (see, for example, Table $\left.4 \mathrm{of}^{39}\right)$. We therefore prescribe a flux whose spatial average is $0.1 \mathrm{Wm}^{-2}$, and is larger locally

over ridges. At a steady state the average flux escaping the ocean through the thick ice cover is therefore also $0.1 \mathrm{~W} \mathrm{~m}^{-2}$. Fig. SI-2 shows the hydrothermal forcing of all three models shown in the paper. The Neoproterozoic flux may have been slightly larger than that of present-day, but the difference is expected to be small relative to other uncertainties, so that modern values are used here.

Most ocean models cannot incorporate an ice cover thicker than their upper level, which is on the order of 5-50 meters. It is, however, important to use a thick shelf ice formulation as done here, as representing thick shelf ice as thin sea ice is known to lead to biases in modeling present-day deep water formation around Antarctica due to the induced biases in fresh water fluxes due to melting/ freezing ${ }^{40,41}$. An alternative to our thick ice-shelf formulation was used by $^{11}$ who employed a dynamic re-scaling of the vertical coordinate ${ }^{42}$.

\section{Derivation of the solution for the 2D flow field}

Consider the zonal equatorial jets seen for example in Fig. 1. Differentiate the hydrostatic equation in $y$ and integrate in $z$ to find $p_{y}=g \rho_{y} z+F(y)$, and assume this meridional pressure 
gradient set by the differential geothermal heating to be approximately constant in latitude $y$ around the equator. The meridional momentum equation then leads to an expression for $u$, and the zonal momentum equation to an expression for $v$. Requiring the vertically integrated meridional flow to vanish due to mass conservation, we find $F(y)$, giving,

$$
u \sim g \rho_{y}(z+H / 2) /\left(\beta \rho_{0}\right) \frac{1}{y}, \quad v \sim 2 v_{h} g \rho_{y}(z+H / 2) /\left(\beta^{2} \rho_{0}\right) \frac{1}{y^{4}} .
$$

If the geothermal heating and bathymetry are prescribed to be uniform, the MOC is weaker by about $75 \%$, and if the ice-surface temperature $T_{s}(y)$ is also uniform, the MOC vanishes. This suggests that the atmospheric forcing via $T_{s}(y)$ is responsible for about $25 \%$ of the $\mathrm{MOC}$, in spite of the thick ice cover. The atmospheric driving of the snowball ocean, and of the MOC in particular, is via its effect on melting rates at high vs. low latitudes. This difference mostly depends on the equator to pole atmospheric temperature difference, and if the $\mathrm{CO}_{2}$ is increased, for example, and if the meridional temperature difference is consequently lowered, then the atmospheric driving of the ocean circulation may be weaker. In addition to this, the sensitivity of the ice flow to surface temperatures derived from different $\mathrm{CO}_{2}$ concentrations was explicitly discussed by ${ }^{15}$. When the geothermal forcing is uniform (but the surface temperature $T_{s}(y)$ is still a function of latitude $y$ ), or the ridge with enhanced heating is placed at the equator, the north-south symmetry is still broken, and while the MOC is weaker and could be in either direction depending on initial conditions, the flows are qualitatively similar to the above.

\section{On the eddy field in the high resolution model run}


The relatively strong zonal velocities that develop in the above 2D model near the equator are characterized by a Reynolds number (based on molecular viscosity) that is much greater than one, of $R=u L / v=\left(0.03 \mathrm{~ms}^{-1}\right)\left(2 \cdot 10^{5} \mathrm{~m}\right) /\left(1.8 \cdot 10^{-6} \mathrm{~m}^{2} \mathrm{~s}^{-1}\right) \sim 4 \times 10^{9}$, anticipating a turbulent flow. In addition, the meridional gradient of vorticity $\left(\beta-u_{y y}\right)$ changes sign as function of latitude, indicating that eddies may develop due to barotropic instability. It is also possible that the eddy field may be able to extract available potential energy from the (weak) meridional density gradient.

The eddy motions seen in our high resolution run are characterized by a velocity scale of $\mathrm{u}^{\prime} \sim 0.02 \mathrm{~ms}^{-1}$ and a length scale of $\ell \sim 100 \mathrm{~km}$ (Fig. 2c). These scales can be used to estimate a mixing-length eddy viscosity of $v_{\mathrm{h}} \sim u^{\prime} \ell \sim 2 \cdot 10^{3} \mathrm{~m}^{2} \mathrm{~s}^{-1}$. A mixing time scale from low to high latitudes is therefore given by $\tau \sim R^{2} / v_{\mathrm{h}} \sim 500$ years, where $R$ is the Earth radius, not very different from present-day basin-scale mixing rates. This is a lower bound on mixing time scales, as one expects the snowball eddy field to be weaker at the higher latitudes where the mean flows and resulting eddy field are weaker. This is in contrast to the present-day ocean, where eddy generation is strong at mid-to high-latitudes near western boundary currents.

\section{Salinity uncertainties}

Estimating ocean salinity during the Neoproterozoic presents a challenge. We assume the presnowball salinity to be equal to modern, but there is significant evidence that it varied significantly and may have been as high as two times modern ${ }^{43}$; see also some recent reviews of evaporites through time ${ }^{44,45}$. Salinity may have also increased during snowball events if oceans continued to receive a supply of salts through both subglacial runoff and subglacial sediment transport, while evaporite deposition would have been nonexistent. The main effect 
of a higher ocean salinity on our simulation would have been the additional lowering of the freezing temperature which is already quite low relative to modern values due to both high pressure at the ice base and high salinity.

Another source of uncertainty in salinity is our assumed concentration of salt due to land-ice volume equivalent to about $1 \mathrm{~km}$ of sea level. Modeling studies ${ }^{46,47}$ estimate continental ice sheets to be a few km thick after $\sim 100 \mathrm{kyr}$, roughly comparable to East Antarctic Ice-Sheet with mean thickness of $2.15 \mathrm{~km}^{48}$. In addition, geological relationships ${ }^{49}$ estimated a postglacial sea-level rise of $1.5 \mathrm{~km}$, which is equivalent to melting $3.3 \mathrm{~km}$ thick grounded ice sheets on all continents and oceanic platforms. We conclude that although no tight constraint on land ice exists, $1 \mathrm{~km}$ thick ice-sheets seem to be within the range of current estimates.

Yet another important salinity-related issue is the possibility of fresh water input from landbased sub-glacial flows. Such fresh water flow at the ocean surface, which may develop should there be any open coastal water, could be mixed down by the strong vertical convective mixing. Yet, if the fresh water input is strong enough, it could lead to a weak local coastal stratification as seen in our solution over the ridge due to melting there (Fig. 1b). This scenario remains speculative as it hinges on the existence of open coastal water, which our model does not explicitly predict. 
31. Li, D. \& Pierrehumbert, R. T. Sea glacier flow and dust transport on Snowball Earth. Geophys. Res. Lett. 38, 10.1029/2011GL048991 (2011).

32. Goodman, J. C. Through thick and thin: Marine and meteoric ice in a "Snowball Earth" climate. Geophys. Res. Lett. 33, 10.1029/2006GL026840 (2006).

33. Pollard, D. \& Kasting, J. F. Reply to comment by Stephen G. Warren and Richard E. Brandt on "Snowball Earth: A thin-ice solution with flowing sea glaciers". J. Geophys. Res. 111 (2006).

34. Morland, L. Unconfined ice-shelf flow. In van der Veen, C. \& Oerlemans, J. (eds.) Dynamics of the West Antarctic Ice Sheet (D. Reidel, Boston, 1987).

35. MacAyeal, D. EISMINT: Lessons in ice-sheet modeling. Tech. Rep., University of Chicago, Chicago, Illinois (1997).

36. Gent, P. R. \& McWilliams, J. C. Isopycnal mixing in ocean circulation models. J. Phys. Oceanogr. 20, 150-155 (1990).

37. Leith, C. E. Stochastic models of chaotic systems. Physica D 98, 481-491 (1996).

38. Adcroft, A., Scott, J. R. \& Marotzke, J. Impact of geothermal heating on the global ocean circulation. Geophys. Res. Lett. 28, 17351738, doi:10.1029/2000GL012182 (2001).

39. Pollack, H., Hurter, S. \& Johnson, J. Heat flow from the Earth's interior: analysis of the global data set. Rev. Geophys. 31, 267-280 (1993). 
40. Hellmer, H., Schodlok, M., Wenzel, M. \& Schr"oter, J. On the influence of adequate Weddell Sea characteristics in a large-scale global ocean circulation model. Ocean Dyn. 55, 88-99 (2005).

41. Thoma, M., Grosfeld, K. \& Lange, M. The impact of the Eastern Weddell ice shelves on water masses in the Eastern Weddell Sea. J. Geophys. Res. 111, C12010 (2006).

42. Campin, J., Marshall, J. \& Ferreira, D. Sea ice-ocean coupling using a rescaled vertical coordinate z. Ocean Modelling 24, 1-14 (2008).

43. Knauth, L. Temperature and salinity history of the Precambrian ocean: implications for the course of microbial evolution. Palaeogeography, Palaeoclimatology, Palaeoecology 219, 5369 (2005).

44. Warren, J. Evaporites through time: Tectonic, climatic and eustatic controls in marine and nonmarine deposits. Earth-Sci. Rev. 98, 217-268 (2010).

45. Evans, D. A. D. Proterozoic low orbital obliquity and axial-dipolar geomagnetic field from evaporite palaeolatitudes. Nature 444, 51-55 (2006).

46. Donnadieu, Y., Fluteau, F., Ramstein, G., Ritz, C. \& Besse, J. Is there a conflict between the Neoproterozoic glacial deposits and the snowball Earth interpretation: an improved understanding with numerical modeling. Earth Planet. Sci. Lett. 208, 101-112 (2003).

47. Pollard, D. \& Kasting, J. Climate-ice sheet simulations of Neoproterozoic glaciation before and after collapse to Snowball Earth. Geophysical Monograph series 146, 91-105 (2004).

48. Lythe, M., Vaughan, D. et al. Bedmap: A new ice thickness and subglacial topographic model of Antarctica. J. Geophys. Res. 106, 11335-11351 (2001). 
49. Hoffman, P. F. Strange bedfellows: glacial diamictite and cap carbonate from the Marinoan (635) glaciation in Namibia. Sedimentology 58, 57-119 (2011). 
a Temperature $(\mathrm{C})$

b Salinity (ppt)
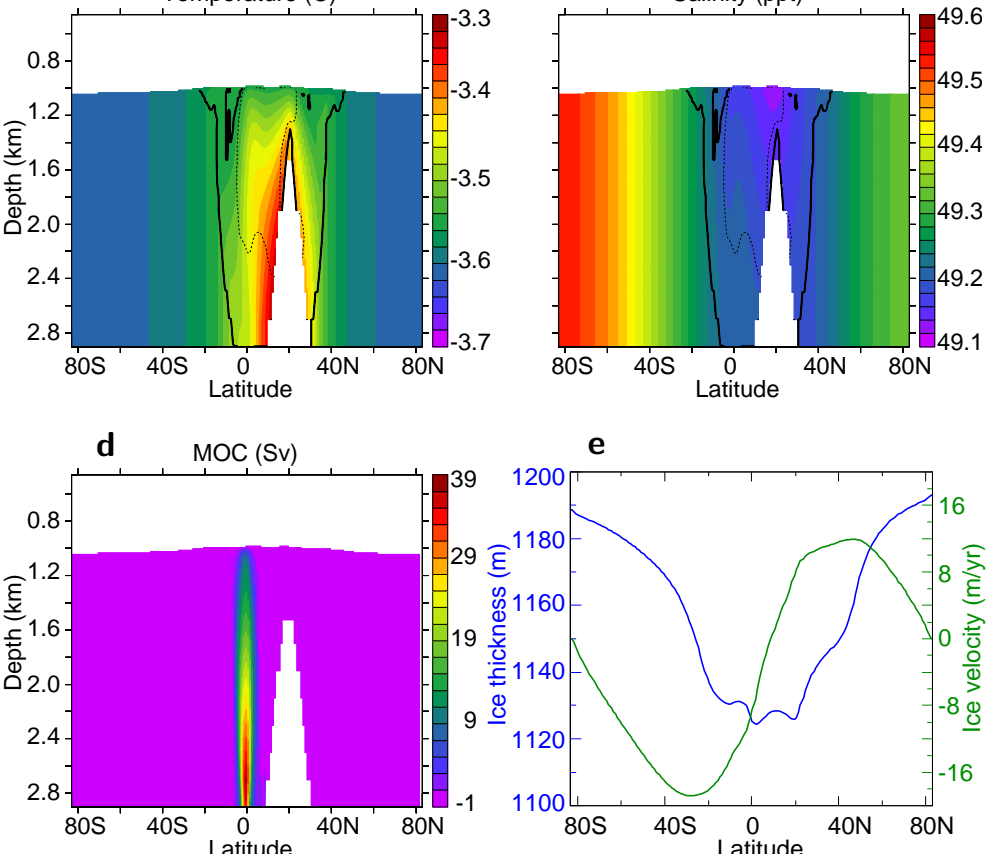

C Zonal velocity $(\mathrm{cm} / \mathrm{s})$
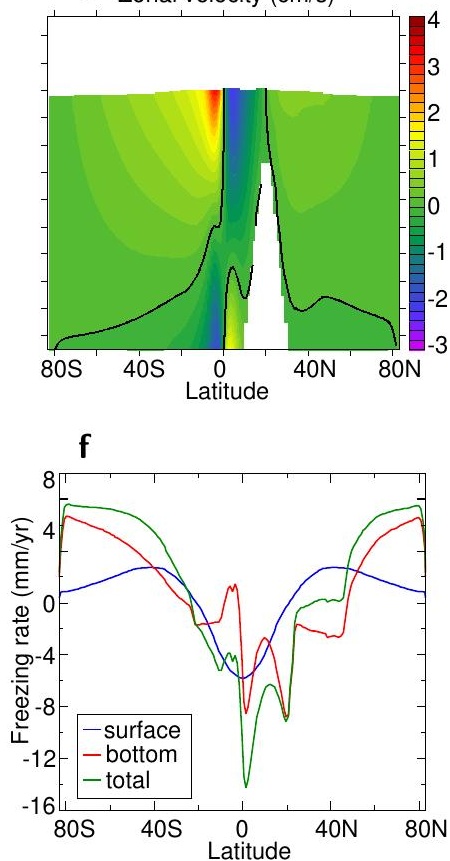


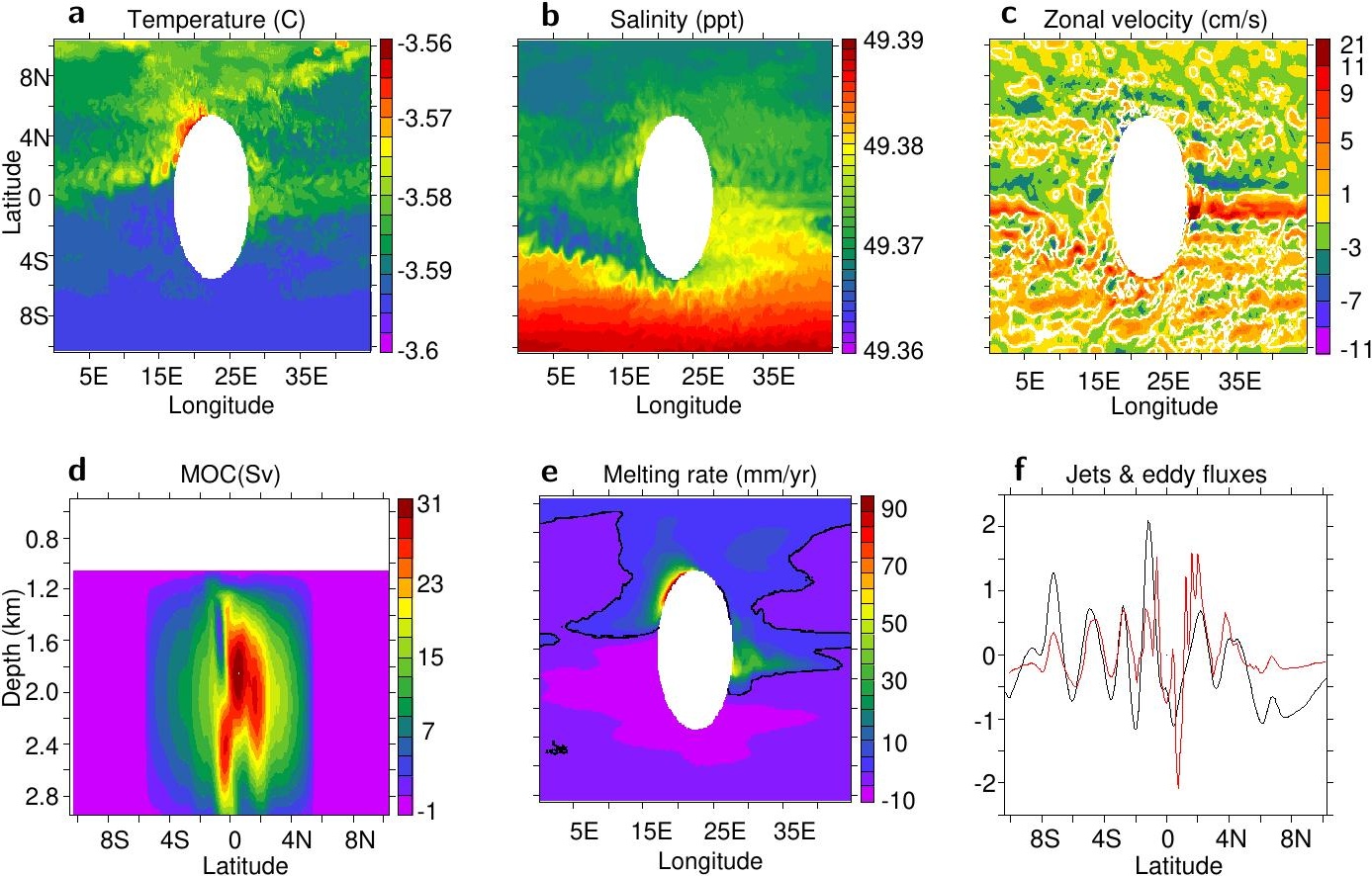




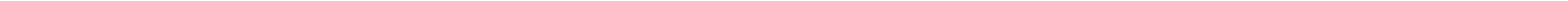

